\title{
Effects of High-Intensity Interval Walking Training on Physical Fitness and Blood Pressure in Middle-Aged and Older People
}

\author{
Ken-ichi Nemoto, MS; Hirokazu Gen-no, PhD; Shizue Masuki, PhD; Kazunobu Okazaki, PhD; \\ and Hiroshi Nose, MD, PhD
}

\begin{abstract}
OBJECTIVE: To examine whether high-intensity interval walking training increased thigh muscle strength and peak aerobic capacity and reduced blood pressure more than moderateintensity continuous walking training.

PARTICIPANTS AND METHODS: From May 18, 2004, to October 15, 2004 (5-month study period), 60 men and 186 women with a mean $\pm S D$ age of $63 \pm 6$ years were randomly divided into 3 groups: no walking training, moderate-intensity continuous walking training, and high-intensity interval walking training. Participants in the moderate-intensity continuous walking training group were instructed to walk at approximately $50 \%$ of their peak aerobic capacity for walking, using a pedometer to verify that they took 8000 steps or more per day for 4 or more days per week. Those in the high-intensity interval walking training group, who were monitored by accelerometry, were instructed to repeat 5 or more sets of 3-minute low-intensity walking at $40 \%$ of peak aerobic capacity for walking followed by a 3-minute high-intensity walking above $70 \%$ of peak aerobic capacity for walking per day for 4 or more days per week. Isometric knee extension and flexion forces, peak aerobic capacity for cycling, and peak aerobic capacity for walking were all measured both before and after training.
\end{abstract}

RESULTS: The targets were met by 9 of 25 men and 37 of 59 women in the no walking training group, by 8 of 16 men and 43 of 59 women in the moderate-intensity continuous walking training group, and by 11 of 19 men and 31 of 68 women in the highintensity interval walking training group. In the high-intensity interval walking training group, isometric knee extension increased by $13 \%$, isometric knee flexion by $17 \%$, peak aerobic capacity for cycling by $8 \%$, and peak aerobic capacity for walking by $9 \%$ (all, $P<.001$ ), all of which were significantly greater than the increases observed in the moderate-intensity continuous walking training group (all, $P<01$ ). Moreover, the reduction in resting systolic blood pressure was higher for the high-intensity interval walking training group $(P=.01)$.

CONCLUSION: High-intensity interval walking may protect against age-associated increases in blood pressure and decreases in thigh muscle strength and peak aerobic capacity.

Mayo Clin Proc. 2007;82(7):803-811

$1 \mathrm{RM}=$ one repetition maximum; $\mathrm{BMI}=$ body mass index; $\mathrm{DBP}=$ diastolic blood pressure; $\mathrm{HR}=$ heart rate; $\mathrm{RPE}=$ rate of perceived exertion; $\mathrm{SBP}=$ systolic blood pressure; $\dot{\mathrm{V}}_{2 \text { peak }}=$ peak aerobic capacity

$\mathrm{T}$ he rapid growth in the elderly population in many countries has highlighted the importance of exercise training to decrease the likelihood of disability and ageassociated disease, promote independence, and enhance quality of life. ${ }^{1}$ Moderately paced (about $6 \mathrm{~km} / \mathrm{h}$ ) walking, thought to protect against disability and age-associated diseases, has been widely recommended to middle-aged and older people. However, that pace may not be intense enough to increase peak aerobic capacity $\left(\mathrm{VO}_{2 \text { peak }}\right)$ and other markers of physical fitness. Indeed, a higher intensity of aerobic exercise $\left(>50 \% \quad \mathrm{VO}_{2 \text { peak }}\right)$ has been recommended in recent guidelines to increase $\mathrm{VO}_{2 \text { peak }}$ in older people. ${ }^{2}$ However, few regimens in the field provide this increased intensity of aerobic exercise while providing the ease of participation of walking.

Walking at submaximal velocity could be one such regimen. We found that the heart rate $(\mathrm{HR})$ in older men and women walking at the maximal velocity almost reached the age-expected maximal values, ${ }^{3}$ suggesting that $\mathrm{VO}_{2 \text { peak }}$ would be increased in older people if For editorial comment, see page 797 walking training was performed at a higher intensity than that recommended by current guidelines. ${ }^{2}$ Furthermore, we recently observed that cycling exercise training at moderate to high intensity increased thigh muscle strength and mass in older men, ${ }^{4,5}$ suggesting that, like traditional resistance training, aerobic exercise training, if performed at the required intensity, can increase thigh muscle strength in older people. On the basis of these findings, we surmised that high-intensity walking training could increase $\mathrm{VO}_{2 \text { peak }}$ and muscle mass and strength in older people. Moreover, we surmised that high-intensity walking training would lead to a greater reduction in blood pressure because the effects of aerobic training on resting blood pressure were reportedly enhanced as the intensity increased into the range of $40 \%$ to $70 \%$ of $\mathrm{VO}_{2 \text { peak }}{ }^{6}$

Our study examined the hypotheses that walking training at more than $70 \%$ of maximal intensity would result in greater increases in thigh muscle strength and $\mathrm{VO}_{2 \text { peak }}$ and a greater reduction in resting blood pressure in older men and women than walking of moderate intensity. If such gains are indeed observed, it would suggest that

From the Department of Sports Medical Sciences, Shinshu University Graduate School of Medicine, Matsumoto, Japan.

This study was supported in part by grants from the Ministry of Health, Labor, and Welfare (Comprehensive Research on Aging and Health), the Japan Society for Promotion of Science, and the Ministry of Economy, Trade, and Industry of Japan.

Address reprint requests and correspondence to Hiroshi Nose, MD, PhD, Department of Sports Medical Sciences, Shinshu University Graduate School of Medicine, 3-1-1 Asahi, Matsumoto 390-8621, Japan (e-mail: nosehir @sch.md.shinshu-u.ac.jp).

() 2007 Mayo Foundation for Medical Education and Research 


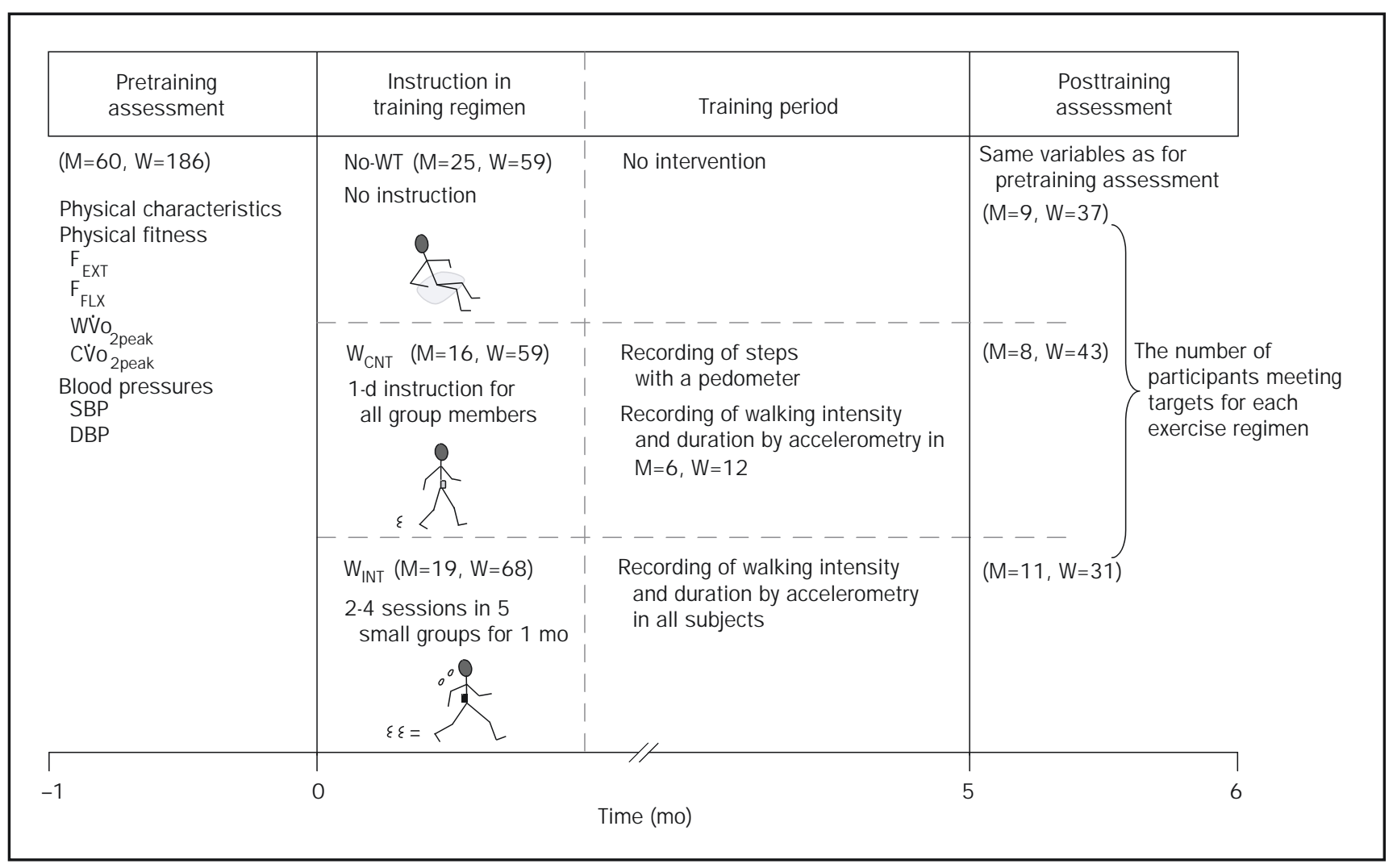

FIGURE 1. Study procedures. $C \dot{V}_{0_{\text {peak }}}=$ peak aerobic capacity by graded cycling; $\mathrm{DBP}=$ diastolic blood pressure; $\mathrm{F}_{\mathrm{EXT}}=$ is ometric knee extension force; $F_{F L X}=$ isometric knee flexion force; $M=$ men; no-WT = no walking training group; $S B P=$ systolic bloọd pressure; $W=$ women; $W_{C N T}=$ moderate-intensity continuous walking training group; $\mathrm{W}_{\mathrm{INT}}=$ high-intensity interval walking training group; $\mathrm{WV}_{\mathrm{Z}_{2} \text { peak }}=$ peak aerobic capacity by graded walking.

middle-aged and elderly people could participate in exercise training calibrated to their individual physical fitness to decrease disability and age-associated diseases more effectively.

\section{PARTICIPANTS AND METHODS}

Once the study protocol (Figure 1) had been approved by the Review Board on Human Experiments, Shinshu University School of Medicine, Matsumoto, Japan, 246 healthy, nonsmoking middle-aged and older adults (44-78 years) with no history of cardiovascular or pulmonary diseases gave written informed consent and were enrolled in the study. Of the study participants, 60 were men and 186 were women. At first, we intended to divide participants randomly into 3 groups, each with 20 men and 62 women: no walking training, moderate-intensity continuous walking training, and high-intensity interval walking training. However, a few of the participants were married couples and wanted to join the same group, and others, who lived a distance from an administrative center, wished to be as- signed to the interval walking group so that they could visit a local community office nearer their homes. For these reasons, minor reassignments were made, resulting in 25 men and 59 women in the no walking training group, 16 men and 59 women in the moderate-intensity continuous walking training group, and 19 men and 68 women in the high-intensity interval walking training group.

Participants in the no walking training group were instructed to maintain a sedentary lifestyle. Those in the continuous walking group were invited to the administrative center at the beginning of the program to receive training for their exercise program. They were instructed to walk more than 8000 steps per day at approximately $50 \%$ $\mathrm{VO}_{2 \text { peak }}$ for walking for a minimum of 4 days per week. Participants used a pedometer (Omron, JH-005, Kyoto, Japan) to monitor their steps and chose a time each day to complete the exercise program. Once a month, they visited the administrative center so that their compliance with the training program could be reviewed.

The subjects in the high-intensity interval walking training group were divided into 5 subgroups of 10 to 20 
TABLE 1. Energy Expenditure During Training in Moderate-Intensity Continuous Walking and High-Intensity Interval Walking Groups*

\begin{tabular}{|c|c|c|c|c|}
\hline & \multicolumn{2}{|c|}{ Moderate-intensity continuous walking group } & \multicolumn{2}{|c|}{ High-intensity interval walking group } \\
\hline & $\begin{array}{c}\text { Men, } n=6 \\
(n=8)\end{array}$ & $\begin{array}{l}\text { Women, } n=12 \\
\quad(n=43)\end{array}$ & $\begin{array}{c}\text { Men } \\
(\mathrm{n}=11)\end{array}$ & $\begin{array}{l}\text { Women } \\
(\mathrm{n}=31)\end{array}$ \\
\hline Walking days per week & $4.4 \pm 0.1(4.9 \pm 0.3)$ & $4.5 \pm 0.1(4.8 \pm 0.1)$ & $4.5 \pm 0.1$ & $4.5 \pm 0.1$ \\
\hline Steps per day & $9833 \pm 260(10,564 \pm 267)$ & $9439 \pm 197(9705 \pm 180)$ & $9166 \pm 195$ & $7874 \pm 162 \dagger$ \\
\hline Energy expenditure $(\mathrm{mLO} /$ day $)$ & $54,656 \pm 707$ & $37,880 \pm 357$ & $54,542 \pm 2539$ & $41,003 \pm 1111$ \\
\hline Walking time(min/day) & $66 \pm 1(66 \pm 3)$ & $61 \pm 1(61 \pm 1)$ & $55 \pm 3 \neq$ & $51 \pm 1 \dagger$ \\
\hline Walking intensity $\left(\mathrm{mLO}_{2} / \mathrm{min}\right)$ & $831 \pm 13$ & $626 \pm 9$ & $992 \pm 15 \dagger$ & $807 \pm 17 \dagger$ \\
\hline Fast walking time (min/day) & NA & NA & $35 \pm 2$ & $32 \pm 1$ \\
\hline Walking intensity during fast walking $\left(\mathrm{mLO}_{2} / \mathrm{min}\right)$ & NA & NA & $1205 \pm 22$ & $961 \pm 26$ \\
\hline Slow walking time $(\mathrm{min} /$ day $)$ & NA & NA & $20 \pm 1$ & $18 \pm 1$ \\
\hline Walking intensity during slow walking $\left(\mathrm{mLO}_{2} / \mathrm{min}\right)$ & NA & NA & $618 \pm 11$ & $538 \pm 9$ \\
\hline
\end{tabular}

$* \mathrm{NA}=$ not applicable. Values are mean \pm SE . First set of values given for each variable in the moderate-intensity continuous walking group are for the 6 men and 12 women who carried an accelerometer during walking. The values in parentheses are those for all members ( 8 men, 43 women) of this group included in the study. Significantly different from values in moderate-intensity continuous walking group $(\dagger P<.001, \ddagger P=.003$ ).

subjects each. Before the start of the study, participants were invited to a community office near their homes and received instruction in the exercise program. They were told to repeat the following regimen 4 or more times per week: 5 or more sets of 2- to 3-minute low-intensity walking intervals (at approximately $40 \%$ of the pretraining $\mathrm{VO}_{2 \text { peak }}$ ), followed by a 3-minute interval of high-intensity walking $\left(>70 \%\right.$ but $<85 \% \mathrm{Vo}_{2 \text { peak }}$ for walking). The intensity and steps were monitored with a triaxial accelerometer carried on the back (Active Tracer 301, GMS, Tokyo, Japan $)^{3}$ and a pedometer, respectively. A beeping signal alerted participants when a change of intensity was scheduled. This method of instruction was continued for the first month of the regimen until the subjects had mastered high-intensity interval walking.

Once participants had learned the program, they could choose the time at which to perform it each day. Every 2 weeks the participants visited a local office, and data from the tracking devices were transferred to a central server at the administrative center through the Internet for automatic analysis and reporting. Trainers used these reports to track daily walking intensity and other parameters given in Table 1 to instruct participants on how best to achieve the target levels. If targets were not met, the trainer encouraged the participants to increase their efforts to achieve them.

In the interval walking group, all participants were equipped with the accelerometer mentioned earlier and a pedometer to measure daily walking intensity and steps, respectively. However, because we had a limited number of accelerometers, 18 ( 12 women, 6 men) of 75 participants in the continuous walking group carried the accelerometer for measuring walking intensity, while all had a pedometer for measuring steps. The training was performed between May 18, 2004, and October 15, 2004, during which time the average atmospheric temperature was $13^{\circ}$ to $25^{\circ} \mathrm{C}$ and relative humidity was $60 \%$ to $80 \%$.
Number of Participants in the Analyses

Of the participants enrolled in the study, the following completed 5 months of training and returned to the laboratory for a physical fitness test: 13 men and 46 women in the no walking training group, 13 men and 49 women in the moderate-intensity continuous walking training group, and 15 men and 53 women in the high-intensity interval walking training group. Those who completed training were asked to fill out a survey; the answers were used to determine whether they had met the criteria given to them at the beginning of the regimen.

In the no walking training group, 13 subjects were excluded from the analyses because they reported walking 30 to 60 minutes 2 to 3 days per week. In the continuous walking group, 3 subjects were excluded because they did not record their daily steps and 8 because their steps per day were fewer than 5000 and because they walked fewer than 2 days per week. In the interval walking group, 18 participants were excluded because they did not record their daily walking intensity and another 8 because they performed only moderate-intensity continuous walking, ie, taking fewer than 4000 steps a day and exercising fewer than 30 minutes a day for fewer than 2 days per week.

The criteria for inclusion in the study were met by 9 men and 37 women in the no walking training group (55\% of the initial number), 8 men and 43 women in the moderateintensity continuous walking training group (68\%), and 11 men and 31 women in the high-intensity interval walking training group (48\%).

\section{MeAsurements}

Blood pressures, $\mathrm{Vo}_{2 \text { peak }}$ by graded cycling exercise and by graded walking exercise, and isometric knee extension and flexion forces were measured before and after the continuous and interval walking group regimens; measurements for the no walking training group were obtained at the same time as for the other groups. 
TABLE 2. Physical Characteristics of Participants in Training Groups: Men vs Women

\begin{tabular}{lccc}
\hline & $\begin{array}{c}\text { No walking } \\
(P \text { value })\end{array}$ & $\begin{array}{c}\text { Moderate-intensity } \\
\text { continuous walking } \\
(P \text { value })\end{array}$ & $\begin{array}{c}\text { High-intensity } \\
\text { interval walking } \\
(P \text { value })\end{array}$ \\
\hline Age & .11 & .005 & .048 \\
Height & .001 & $<.001$ & $<.001$ \\
Weight & .01 & .003 & $<.001$ \\
\hline
\end{tabular}

Peak Aerobic Capacity by Graded Walking. After baseline measurements at rest for 3 minutes, subjects with a triaxial accelerometer on their back walked for 3 minutes on a flat floor at 3 graded subjective velocities: slow, moderate, and fast. At the same time, 3-dimensional acceleration and HR with the electrocardiogram were measured at 10-millisecond intervals and recorded with 5-second memories as averaged values. ${ }^{3}$ The total impulse from an accelerometer $^{7}$ was transferred to a computer and converted to oxygen consumption rate using a previously reported equation. ${ }^{3}$ Peak aerobic capacity and peak HR for walking values are those for the last 30 seconds at maximal walking velocity.

Knee Extension and Flexion Forces and $\hat{V}_{2 \text { peak }}$ by Graded Cycling. No earlier than day 4 after the measurement of $\mathrm{VO}_{2 \text { peak }}$ by walking, knee extension and flexion forces were measured on each side of the knee with a dynamometer (Biodex 3, Biodex Medical System, Shirley, $\mathrm{NY}$ ) and the 2 measurements averaged for reporting. The validity of $\mathrm{VO}_{2 \text { peak }}$ by graded walking determined earlier on each subject was confirmed by determining $\mathrm{Vo}_{2 \text { peak }}$ by graded cycling using expired gas analysis (AE260, Minato, Tokyo, Japan) by averaging the values for the 30 seconds at maximal intensity with peak HR by electrocardiography (Life Scope $8 \mathrm{M}$, Nihon Kohden, Toyko, Japan), as described previously. ${ }^{4}$

These measurements before and after training were performed by the same investigator according to the same protocol.

Blood Pressures. Before $\mathrm{VO}_{2 \text { peak }}$ by walking was determined, systolic (SBP) and diastolic (DBP) blood pressures were measured by auscultation after the participant had been sitting for 10 minutes in a room with an ambient temperature of $25^{\circ} \mathrm{C}$ and relative humidity of approximately $50 \%$.

\section{Statistical Analyses}

We used 2-way analysis of variance to determine any significant differences among the groups or between men and women in preregimen physical characteristics and training program achievements. An analysis of covariance with the pretraining values included as a covariate ${ }^{8}$ was used to determine any significant differences among the groups in postregimen physical characteristics, cardiovascular vari- ables, muscle strength, and $\mathrm{VO}_{2 \text { peak }}$. Analysis of covariance was also used to determine if the changes in these values for a given group were statistically different from the changes noted for the other groups. The effects of each training regimen on these variables were tested using a 2way (sex; before or after training) analysis of variance for repeated measures. The statistical power to detect their significant changes after training in the continuous and interval walking groups was $>0.8$ at $\alpha$ of 0.05 except for SBP in men from the continuous walking group (0.74) and DBP in men from the interval walking group (0.53). Subsequent post hoc tests to determine significant differences in the various pairwise comparisons were performed with Fisher exact test. Values are presented as means \pm SE except as noted. The null hypothesis was rejected at $P<.05$.

We did not perform an intention-to-treat analysis ${ }^{9}$ because we were unable to determine the effects of training on participants who did not return to the laboratory for a physical fitness test after training. Moreover, for our analyses, we needed to exclude the participants who did not achieve the targets set before the start of training for each of the training regimens because the purpose of this study was to assess if the high-intensity interval walking regimen, when performed as initially directed, improved physical fitness more than the moderate-intensity continuous walking regimen. As a result, we excluded approximately $40 \%$ of the participants in each group from our analyses and reconfirmed that pretraining values for physical characteristics, physical fitness, and cardiovascular variables were not statistically different among the groups.

\section{RESULTS}

Although the number of days walked per week did not significantly differ between the interval and continuous walking groups, the walking time of the interval group was only $83 \%$ of the continuous walking group (Table 1 ). However, despite this difference in walking time, the energy expenditure per day did not differ significantly between the 2 groups ( $P=.66)$ because the interval walking group exercised at a much higher intensity $\left(>70 \% \mathrm{Vo}_{2 \text { peak }}\right)$ than the continuous walking group.

Significantly higher values for age, height, and body weight were observed for men than for women (Table 2), but differences in age in the no-training group $(P=.11)$ and differences among the groups before training were not statistically significant (Table 3). After training, body weight and body mass index (BMI [calculated as weight in kilograms divided by the square of height in meters]) decreased significantly in the women in the continuous (both, $P<.001$ ) and interval (weight, $P=.02$; BMI, $P=.01$ ) walking training groups but increased significantly in the no walk- 
TABLE 3. Physical Characteristics Before and After Training*

\begin{tabular}{|c|c|c|c|c|c|c|c|c|c|c|c|c|}
\hline & \multicolumn{4}{|c|}{ No walking group } & \multicolumn{4}{|c|}{ Moderate-intensity continuous walking group } & \multicolumn{4}{|c|}{ High-intensity interval walking group } \\
\hline & \multicolumn{2}{|c|}{ Men (n=9) } & \multicolumn{2}{|c|}{ Women $(n=37)$} & \multicolumn{2}{|c|}{ Men $(n=8)$} & \multicolumn{2}{|c|}{ Women $(n=43)$} & \multicolumn{2}{|c|}{$\operatorname{Men}(n=11)$} & \multicolumn{2}{|c|}{ Women $(n=31)$} \\
\hline & Before & After & Before & After & Before & After & Before & After & Before & After & Before & After \\
\hline Age (y) & $66 \pm 5$ & NA & $62 \pm 6$ & NA & $67 \pm 5$ & NA & $62 \pm 5$ & NA & $67 \pm 4$ & NA & $64 \pm 6$ & NA \\
\hline $\begin{array}{l}\text { Height } \\
(\mathrm{cm})\end{array}$ & $163 \pm 3$ & NA & $155 \pm 6$ & NA & $165 \pm 8$ & NA & $154 \pm 6$ & NA & $167 \pm 6$ & NA & $153 \pm 6$ & NA \\
\hline $\begin{array}{l}\text { Weight } \\
\text { (kg) }\end{array}$ & $61.1 \pm 2.4$ & $62.0 \pm 2.5$ & $54.1 \pm 1.1$ & $54.9 \pm 1.2 \dagger$ & $62.5 \pm 2.7$ & $61.8 \pm 2.7$ & $54.4 \pm 1.0$ & $53.2 \pm 0.9 \dagger+$ & $63.7 \pm 2.4$ & $62.9 \pm 2.2$ & $53.7 \pm 1.2$ & $52.9 \pm 1.2 \S \ddagger$ \\
\hline $\begin{array}{l}\mathrm{BMI} \\
\quad\left(\mathrm{kg} / \mathrm{m}^{2}\right)\end{array}$ & $23.1 \pm 0.8$ & $23.5 \pm 0.9$ & $22.7 \pm 0.5$ & $23.0 \pm 0.5 \dagger$ & $23.0 \pm 1.1$ & $22.7 \pm 1.2$ & $22.8 \pm 0.4$ & $22.3 \pm 0.3+\neq$ & $22.9 \pm 0.8$ & $22.6 \pm 0.7$ & $22.9 \pm 0.5$ & $22.5 \pm 0.5 \| \Psi$ \\
\hline
\end{tabular}

*BMI = body mass index; NA = not applicable. Values are mean \pm SD for age and height, and mean \pm SE for body weight and BMI. Significantly different from pretraining values $(\dagger P<.001 ; \S P=.02 ; \| P=.01)$. Significantly different from corresponding values in no walking training group ( $\ddagger P<.001, \rrbracket[P=.004)$.

ing training group $(P<.001)$ to levels that were significantly higher than those of women in both the continuous (both, $P<.001$ ) and interval (weight, $P<.001$; BMI, $P<.004$ ) walking groups.

Peak aerobic capacities and thigh muscle strength were significantly higher in men than in women (Table 4), but no significant differences were observed among participants in the 3 groups before training $(P=.43-P=.93)$. Before training, SBP and DBP did not differ significantly among the groups $(P=.13-P=.67)$, but after training a significant decrease in SBP and DBP was noted in the interval walking group (both, $P<.001$, when the values in men and women were pooled) and a significant decrease in SBP in the interval walking group compared with the no walking training group $(P<.001)$. Similarly, in the high-intensity interval walking training group, knee extension and flexion forces increased significantly after training (both, $P<.001$ ), and these values were significantly higher than those observed in the no walking training group $(P<.001)$ and in the moderate-intensity continuous walking training group $(P<.001)$. Furthermore, in the high-intensity interval walking training group, $\mathrm{VO}_{2 \text { peak }}$ by walking and cycling significantly increased after training (both, $P<.001$ ) to levels that were significantly higher than those observed in the no walking training group (walking, $P<.001$; cycling, $P=.007$ ) and in the moderate-intensity continuous walking group (both, $P<.001)$. In contrast, no significant differences between the continuous walking and no walking training groups were noted for any of the variables, except for a significantly lower SBP after training $(P<.001)$.

As shown in Figure 2, knee extension and flexion forces in the high-intensity interval walking training group increased significantly by $13 \%$ and $17 \%$, respectively (both, $P<.001$ ), and these values were significantly higher than those of the no walking training group (both, $P<.001$ ) and the moderate-intensity continuous walking group (extension, $P<.001$; flexion, $P=.004$ ). In the high-intensity interval walking training group, moreover, significant increases in $\mathrm{VO}_{2 \text { peak }}$ by walking $(9 \%)$ and cycling $(8 \%)$ (both, $P<.001$ ) were observed, and these values were significantly greater than those in the no walking training group (walking, $P<.001$; cycling, $P=.005)$ and in the moderate-intensity continuous walking group (walking, $(P<.001$; cycling, $P=.004)$. Furthermore, in the high-intensity interval walking group, $\mathrm{VO}_{2 \text { peak }}$ by walking increased in 26 of 33 participants with increased knee extension force (79\%), suggesting a close relationship between these variables.

As shown in Figure 3, SBP and DBP for the highintensity interval walking group decreased significantly by $9 \mathrm{~mm} \mathrm{Hg}$ and $5 \mathrm{~mm} \mathrm{Hg}$, respectively (both, $P<.001$ ), and the reduction in SBP after training was significantly greater in the high-intensity interval walking group than in the no walking training group $(P=.002)$ and in the moderateintensity continuous walking group $(P=.01)$. Moreover, SBP decreased in 25 of 33 participants with increased $\mathrm{VO}_{2 \text { peak }}$ for walking in the interval walking group (76\%), suggesting a close relationship between $\mathrm{SBP}$ and $\mathrm{VO}_{2 \text { peak }}$.

\section{DISCUSSION}

The major findings of this study are that high-intensity interval walking resulted in greater increases in $\mathrm{VO}_{2 \text { peak }}$ and thigh muscle strength and a greater reduction in SBP than moderate-intensity continuous walking in older men and women.

We adopted 3 minutes as the walking interval because most participants could not continue to walk at the high intensity for more than 3 minutes because of fatigue. However, they recovered from this fatigue within 2 to 3 minutes, and so we adopted a regimen of a 3-minute interval of high-intensity walking followed by 2 to 3 minutes of lowintensity walking and instructed participants to perform more than 5 sets per day.

In most field studies, HR and rate of perceived exertion (RPE) have been used to monitor relative exercise intensity. However, trainers using HR and RPE methods might find it difficult to instruct participants to perform highintensity interval walking because they would not be able 
TABLE 4. Resting Hemodynamics, Peak Aerobic Capacities, and Thigh Muscle Strength Before and After Training*

\begin{tabular}{|c|c|c|c|c|}
\hline & \multicolumn{4}{|c|}{ No walking training group } \\
\hline & \multicolumn{2}{|c|}{ Men $(n=9)$} & \multicolumn{2}{|c|}{ Women $(n=37)$} \\
\hline & Before & After & Before & After \\
\hline Resting HR (beats/min) & $80 \pm 3$ & $77 \pm 4$ & $79 \pm 1$ & $77 \pm 2$ \\
\hline Resting SBP (mm Hg) & $143 \pm 2$ & $141 \pm 2$ & $142 \pm 3$ & $141 \pm 3$ \\
\hline Resting DBP (mm Hg) & $84 \pm 2$ & $83 \pm 2$ & $83 \pm 2$ & $82 \pm 2$ \\
\hline Peak aerobic capacity for cycling $(\mathrm{mL} / \mathrm{min})$ & $1502 \pm 133$ & $1489 \pm 104$ & $1209 \pm 40$ & $1208 \pm 42$ \\
\hline Peak aerobic capacity for walking ( $\mathrm{mL} / \mathrm{min})$ & $1481 \pm 108$ & $1434 \pm 66$ & $1238 \pm 25$ & $1202 \pm 32$ \\
\hline Peak HR for cycling (beats/min) & $147 \pm 6$ & $146 \pm 6$ & $149 \pm 2$ & $147 \pm 3$ \\
\hline Peak HR for walking (beats/min) & $141 \pm 7$ & $136 \pm 6$ & $145 \pm 2$ & $144 \pm 3$ \\
\hline Isometric knee extension force $(\mathrm{N} \cdot \mathrm{m})$ & $137 \pm 5$ & $134 \pm 4$ & $100 \pm 3$ & $100 \pm 3$ \\
\hline \multirow[t]{4}{*}{ Isometric knee flexion force $(\mathrm{N} \cdot \mathrm{m})$} & $72 \pm 2$ & $73 \pm 3$ & $46 \pm 2$ & $45 \pm 2$ \\
\hline & \multicolumn{4}{|c|}{ Moderate-intensity continuous walking group } \\
\hline & \multicolumn{2}{|c|}{ Men $(n=8)$} & \multicolumn{2}{|c|}{ Women $(n=43)$} \\
\hline & Before & After & Before & After \\
\hline Resting HR, beats/min & $81 \pm 3$ & $79 \pm 3$ & $78 \pm 1$ & $78 \pm 2$ \\
\hline Resting SBP (mm Hg) & $141 \pm 2$ & $138 \pm 2 \dagger$ & $135 \pm 3$ & $132 \pm 3 \neq$ \\
\hline Resting DBP (mm Hg) & $85 \pm 2$ & $83 \pm 2 \S$ & $81 \pm 2$ & $79 \pm 1$ \\
\hline Peak aerobic capacity for cycling $(\mathrm{mL} / \mathrm{min})$ & $1560 \pm 106$ & $1565 \pm 112$ & $1191 \pm 35$ & $1180 \pm 31$ \\
\hline Peak aerobic capacity for walking ( $\mathrm{mL} / \mathrm{min})$ & $1507 \pm 88$ & $1481 \pm 99$ & $1203 \pm 28$ & $1177 \pm 26$ \\
\hline Peak HR for cycling (beats/min) & $149 \pm 4$ & $152 \pm 7$ & $147 \pm 3$ & $145 \pm 3$ \\
\hline Peak HR for walking (beats/min) & $141 \pm 3$ & $142 \pm 5$ & $142 \pm 3$ & $139 \pm 3$ \\
\hline Isometric knee extension force $(\mathrm{N} \cdot \mathrm{m})$ & $138 \pm 6$ & $138 \pm 3$ & $94 \pm 3$ & $95 \pm 3$ \\
\hline \multirow[t]{4}{*}{ Isometric knee flexion force $(\mathrm{N} \cdot \mathrm{m})$} & $73 \pm 2$ & $74 \pm 2$ & $45 \pm 2$ & $48 \pm 2 \S$ \\
\hline & \multicolumn{4}{|c|}{ High-intensity interval walking group } \\
\hline & \multicolumn{2}{|c|}{$\operatorname{Men}(n=11)$} & \multicolumn{2}{|c|}{ Women $(n=31)$} \\
\hline & Before & After & Before & After \\
\hline Resting HR (beats/min) & $75 \pm 3$ & $74 \pm 3$ & $81 \pm 2$ & $78 \pm 1 \dagger$ \\
\hline Resting SBP $(\mathrm{mm} \mathrm{Hg})$ & $146 \pm 2$ & $136 \pm 2 \| \mathbb{| \Phi}$ & $140 \pm 3$ & $132 \pm 2 \|$. \\
\hline Resting DBP (mm Hg) & $87 \pm 3$ & $82 \pm 2 \dagger$ & $85 \pm 2$ & $80 \pm 2 \S$ \\
\hline Peak aerobic capacity for cycling (mL/min) & $1525 \pm 59$ & $1668 \pm 72|| \# * *$ & $1151 \pm 35$ & $1222 \pm 37 \S$ \\
\hline Peak aerobic capacity for walking ( $\mathrm{mL} / \mathrm{min})$ & $1464 \pm 56$ & $1623 \pm 50|| \# * *$ & $1186 \pm 34$ & $1274 \pm 35+4 \dagger \dagger$ \\
\hline Peak HR for cycling (beats/min) & $146 \pm 5$ & $153 \pm 6$ & $144 \pm 2$ & $141 \pm 3$ \\
\hline Peak HR for walking (beats/min) & $142 \pm 4$ & $137 \pm 4$ & $144 \pm 2$ & $139 \pm 2$ \\
\hline Isometric knee extension force $(\mathrm{N} \cdot \mathrm{m})$ & $132 \pm 5$ & $149 \pm 8 \| \# * *$ & $95 \pm 4$ & $106 \pm 4 \| 9 \pm+$ \\
\hline Isometric knee flexion force $(\mathrm{N} \cdot \mathrm{m})$ & $71 \pm 3$ & $81 \pm 3 \| \# * *$ & $44 \pm 2$ & $51 \pm 2|| \# * *$ \\
\hline
\end{tabular}

*DBP $=$ diastolic blood pressure $; \mathrm{HR}=$ heart rate $; \mathrm{N} \cdot \mathrm{m}=$ newton meter; $\mathrm{SBP}=$ systolic blood pressure. Values represent mean $\pm \mathrm{SE}$. Significantly different from pretraining values $(\dagger P<.05, \S P<.01$, and $\| P<.001)$. Significantly different from the corresponding values for the no walking training group ( $([P<.05, \# P<.01$, and $\ddagger P<.001)$. Significantly different from the corresponding values for the moderate-intensity continuous walking group $(* * P<.05, \dagger \dagger P<.01$, and $\$ \uparrow P<.001)$.

to determine absolute walking intensity to a high resolution of 1 minute. For example, after a change in walking speed it takes 1 to 2 minutes for HR to reach a steady level equivalent to the new level of exercise intensity. Moreover, HR and RPE responses are influenced by adaptation to training, environmental conditions, and the physical condition of participants. For these reasons, in our study we chose to use a triaxial accelerometer to monitor exercise intensity during training.

As shown in Figure 2, significant increases in knee extension force $(13 \%)$ and knee flexion force $(17 \%)$ were observed in the high-intensity interval walking training group, increases that were significantly greater than those seen in the moderate-intensity continuous walking training group. The intensity of exercise training used in our study for the high-intensity interval walking training group is not as high as that recommended for increased muscle strength by the current American College of Sports Medicine guidelines for resistance training ( 3 sets of 8 repetitions per day at $80 \%$ of one repetition maximum [1RM], 2 to 3 days pep, week, for 3 months). However, Bemben et al ${ }^{10}$ suggested that the same gains in muscle strength and mass of the lower extremities (approximately $30 \%$ ) could be made in older women with 3 sets 


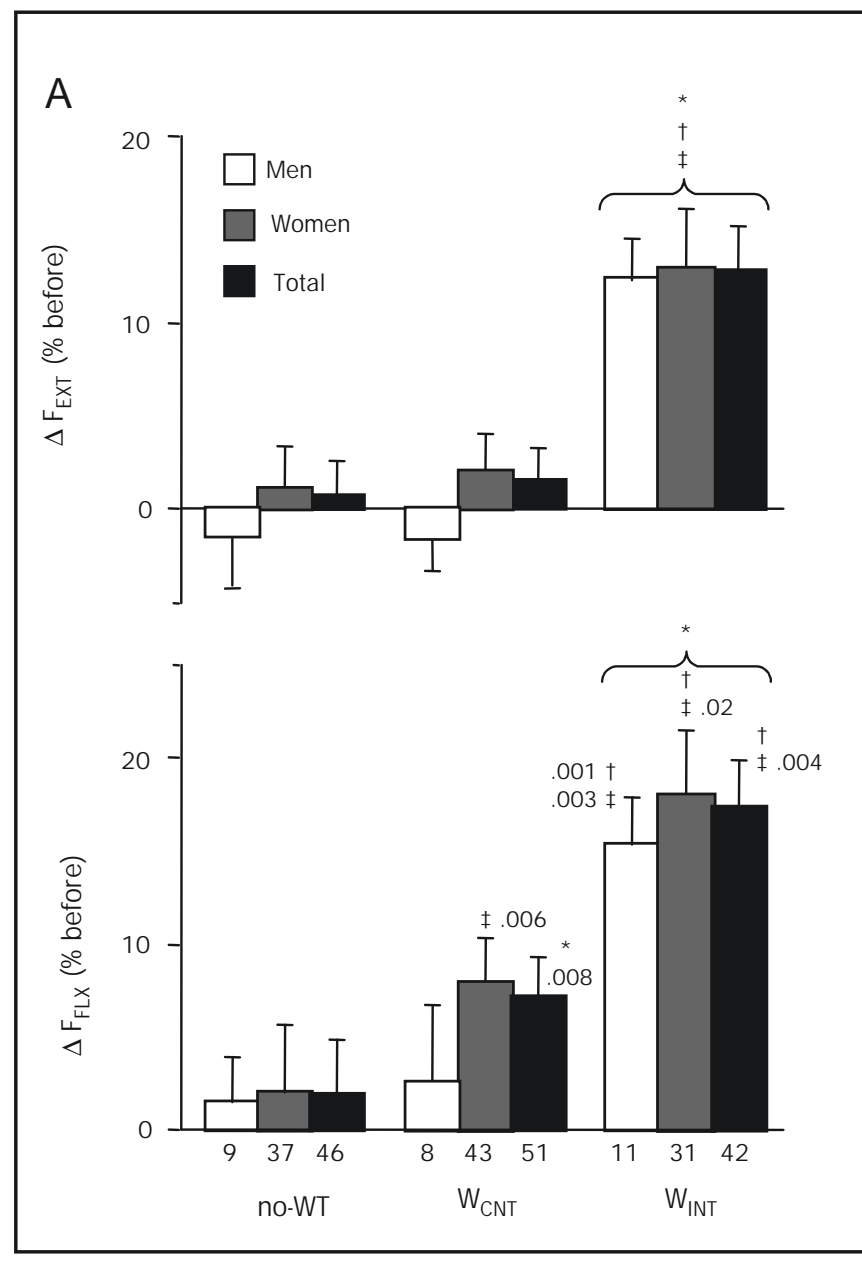

of lower-intensity (40\% 1RM) resistance training repeated 16 times per day, 3 days per week for 6 months, as with 3 sets of high-intensity ( $80 \% 1 \mathrm{RM})$ resistance training repeated 8 times per day for the same period. Similar results were obtained in young subjects. ${ }^{11,12}$ Recently, we showed that isometric knee extension could be increased by $13 \%$ and thigh muscle mass by $8.4 \%$, as measured by magnetic resonance imaging, in older men cycling at $50 \%$ to $80 \%$ of $\mathrm{VO}_{2 \text { peak }}, 60$ minutes per day, 3 days per week, for 18 weeks, but not in those engaging in moderate-intensity continuous walking, ie, approximately 10,000 steps per day, 6 to 7 days per week, for 18 weeks. ${ }^{4,5}$ Thus, like traditional resistance training, higher repetitions of muscle contraction and relaxation above a given intensity may increase thigh muscle strength in older people.

The increase in $\mathrm{VO}_{2 \text { peak }}$ in the high-intensity interval walking group was greater than that in the continuous walking group. Fleg and Lakatta ${ }^{13}$ have suggested that the age-associated decline in $\mathrm{VO}_{2 \text { peak }}$ per kilogram of body weight may be attributable to loss of muscle mass be-
B

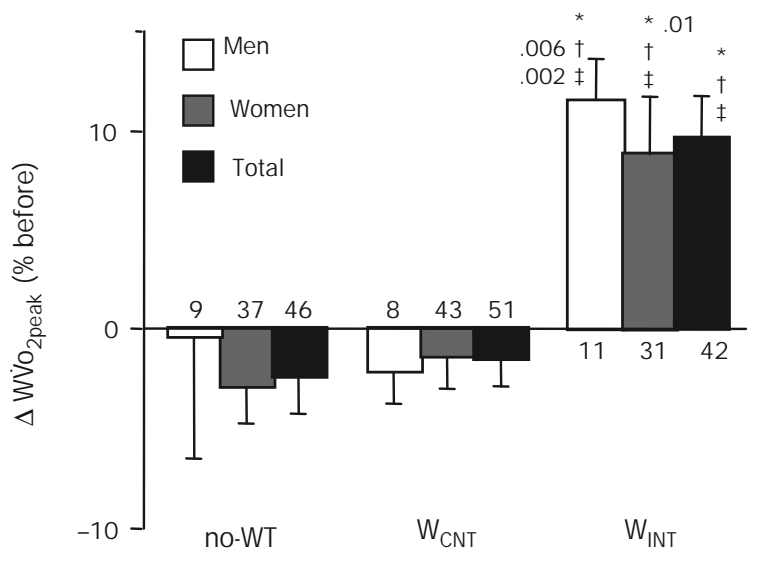

FIGURE 2. Percent changes in isometric knee extension force $\left(F_{\text {EXT }}\right)$ and isometric knee flexion force $\left(F_{F L X}\right)(A)$ and peak aerobic capacity by graded walking $\left(\mathrm{WV}_{\mathrm{O}_{\text {peak }}}\right)$ (B) after training in the no walking training (no-WT), moderate-intensity continuous walking training $\left(\mathrm{W}_{\mathrm{CNT}}\right)$, and high-intensity interval walking training $\left(\mathrm{W}_{\mathrm{INT}}\right)$ groups.

* Significant differences from the pretraining values $(P<.001)$.

$\dagger$ Significant differences from the corresponding values in no-WT $(P<.001)$.

$¥$ Significant differences from the corresponding values in $W_{C N T}$ $(P<.001)$, except in cases where the symbol is presented together with the value. The value indicates the specific $P$ value in each comparison.

cause such declines diminished markedly to only $10 \%$ to $20 \%$ in healthy men and women aged 22 to 87 years in whom 24-hour urinary creatinine excretion, an index of muscle mass, was normalized. Using dual x-ray absorptiometry to test for a number of muscle mass indices, Proctor and Joyner ${ }^{14}$ showed that age-associated decline in $\mathrm{VO}_{2 \text { eak }}$ was associated with a decline in muscle mass. Taken together with our own previous reports, 4,5 these studies suggest that the greater increase in thigh muscle strength or mass in the interval walking group in our current study might have contributed to the greater increase in $\mathrm{VO}_{\text {2peak }}$.

In addition to the increase in thigh muscle mass, an increase in aerobic capacity per unit of muscle mass may contribute to the increase in $\mathrm{VO}_{2 \text { peak }}$. Capillary density and citrate synthetase activity were shown to increase with an increase in mean fiber area after 12 weeks of resistance training in older men. ${ }^{15}$ Cellular oxidative capacity was also enhanced after 6 months of aerobic and resistance training in older patients. ${ }^{16}$ Since aerobic training in older 


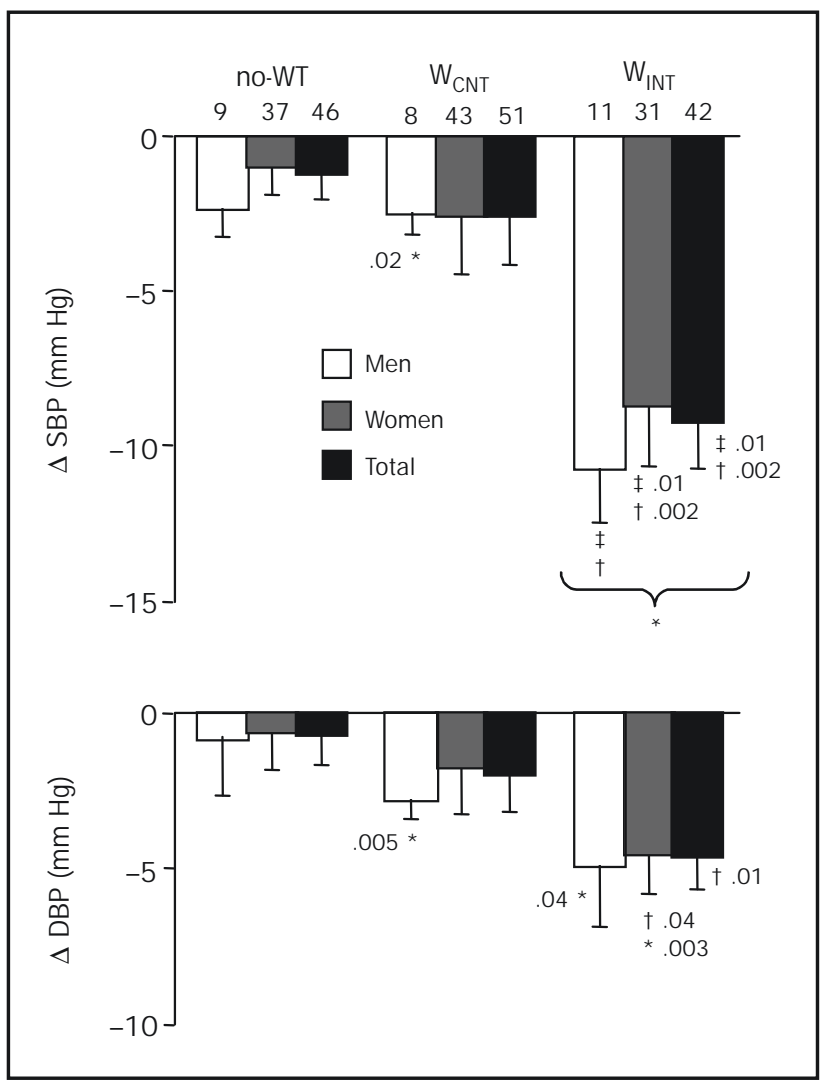

FIGURE 3. Changes in systolic blood pressure (SBP) and diastolic blood pressure (DBP) at rest after training in the no walking training (no-WT), moderate-intensity continuous walking training $\left(\mathrm{W}_{\mathrm{CNT}}\right)$, and high-intensity interval walking training $\left(\mathrm{W}_{\mathrm{INT}}\right)$ groups.

* Significant differences from the pretraining values $(P<.001)$. †Significant differences from the corresponding values in no-WT $(P<.001)$.

$\ddagger$ Significant differences from the corresponding values in $W_{C N T}$ $(P<.001)$, except in cases where the symbol is presented together with the value. The value indicates the specific $P$ value in each comparison.

men was shown not to affect blood volume ${ }^{4}$ and cardiac stroke volume at a given intensity of exercise, ${ }^{17}$ the increase in $\mathrm{VO}_{2 \text { peak }}$ is likely caused by an accelerated oxygen extraction rate in thigh muscle rather than by increased oxygen delivery due to increased maximal cardiac output.

The greatest reductions in blood pressure after training were observed in the high-intensity interval walking training group (Figure 3). In a 1- to 12-year retrospective study of men and women aged 20 to 65 years with no history of hypertension, Blair et $\mathrm{a}^{18}$ showed that subjects with low levels of $\mathrm{VO}_{2 \text { peak }}$ were at higher risk for developing hypertension than were those with high $\mathrm{VO}_{2 \text { peak }}$. Sawada et $\mathrm{al}^{19}$ further showed in a 5-year longitudinal study of men aged 50 years and older that subjects with increased $\mathrm{VO}_{2 \text { peak }}$ were less likely to have increased blood pressure after 5 years than those with unchanged or decreased $\mathrm{VO}_{2 \text { peak }}$. In the current study, the high reduction in SBP occurred in the subjects with increased $\mathrm{VO}_{2 \text { peak }}$. Our study is one of the first prospective attempts to test epidemiological findings, and its findings suggest that blood pressures can be decreased and $\mathrm{VO}_{2 \text { peak }}$ enhanced by even short periods of exercise.

Our study has several potential limitations. First, different monitoring systems were used for the moderateintensity continuous and high-intensity interval walking training groups. Because we had a limited number of triaxial accelerometers, we used pedometers in the moderateintensity continuous walking training group, thinking that steps divided by exercise duration would give us reasonable measures of exercise intensity in this group. We thought it important to use the accelerometers in the highintensity interval walking training group because we wanted to ensure that the desired changes in exercise intensity occurred. Thus, although 2 different monitoring systems were used, they were optimally targeted to the appropriate group and could be used to ensure that subjects meeting inclusion criteria achieved the desired exercise patterns and intensities.

Second, the subjects in the high-intensity interval walking training group, who were divided into 5 small groups, visited the center more frequently (approximately 18 times) and interacted with the trainer more, perhaps influencing the pre- and posttraining blood pressure measurements. However, members of the moderate-intensity continuous walking training group visited the center approximately 11 times and could reasonably be expected to have gained complete familiarity with the testing environment. Thus, we believe it is unlikely that the different monitoring systems and the different style of interaction with the trainer in the continuous and interval walking groups affected the main outcomes of the study.

Third, $30 \%$ of the subjects in the no walking training group, $17 \%$ of those in the moderate-intensity continuous walking training group, and $22 \%$ in the high-intensity interval walking training group did not return to the laboratory for a physical fitness test after training. Another $15 \%$ in the no walking training and moderate-intensity continuous walking training groups and $30 \%$ in the highintensity interval walking training group did not meet the criteria for inclusion in the study. If more opportunities for a physical fitness test and for an explanation of the importance of this study had been given to participants, more of them may have returned to the laboratory. Similarly, if more opportunities to master the interval walking with an accelerometer had been given at an early stage of training, more participants may have met the targets set for that group. However, limitations in staff and facilities made it impossible to provide such opportunities in this study. Given these limitations, we did not include all 
randomized participants in the analysis. Therefore, the possibility exists that the study findings are influenced by selection bias.

In future studies, we will attempt to minimize inconvenience and improve attainment of study targets by use of the Internet. The Internet would allow for remote supervision by a trainer and for self-monitoring of progress by participants, obviating the need for trips to a gymnasium and making attainment of exercise targets more likely. Also, encouraged by the reduction in SBP observed in this study in participants with increased physical fitness, we will examine the effects of genetic background, blood lipid and glucose concentrations, diets, and depressive scores not only on age-associated diseases but also on health care costs.

\section{CONCLUSION}

High-intensity interval walking training might help protect against age-associated reductions in muscle strength and $\mathrm{VO}_{2 \text { peak }}$ and increases in blood pressure. Guidelines for exercise in healthy older adults should encourage at least some higher-intensity component during walking.

\section{REFERENCES}

1. Haskell WL, Phillips WR. Effects of exercise training on health and physical functioning in older persons. In: Nose H, Nadel ER, Morimoto T, eds. The 1997 Nagano Symposium on Sports Sciences. Carmel, Ind: Cooper Publishing Group; 1998:399-417.

2. Armstrong L, Balady GJ, Berry MJ, et al. General principles of exercise prescription. In: Whaley MH, ed. ACSM's Guidelines for Exercise Testing and Prescription. 7th ed. Baltimore, Md: Williams \&Wilkins; 2006:133-173.

3. Iwashita S, Takeno Y, Okazaki K, et al. Triaxial accelerometry to evaluate walking efficiency in older subjects. Med Sci Sports Exerc. 2003;35:1766-1772.

4. Okazaki K, Kamijo Y, Takeno Y, Okumoto T, Masuki S, Nose H. Effects of exercise training on thermoregulatory responses and blood volume in older men. J Appl Physiol. 2002;93:1630-1637.
5. Okazaki K, Kamijo Y, Takeno Y, et al. The effects of aerobic or resistance training on blood volume, thigh muscle mass, and peak aerobic power in older men [abstract] [in Japanese]. Jpn J Phys Fitness Sports Med. 2001;50:885. Abstract 305.

6. Armstrong L, Balady GJ, Berry MJ, et al. Other clinical conditions influencing exercise prescription. In: Whaley $\mathrm{MH}$, ed. ACSM's Guidelines for Exercise Testing and Prescription. 7th ed. Baltimore, Md: Williams \& Wilkins; 2006:205-236.

7. Bouten CV, Westerterp KR, Verduin M, Janssen JD. Assessment of energy expenditure for physical activity using a triaxial accelerometer. Med Sci Sports Exerc. 1994;26:1516-1523.

8. Vickers AJ, Altman DG. Statistics notes: analysing controlled trials with baseline and follow up measurements. BMJ. 2001;323:1123-1124.

9. Hollis S, Campbell F. What is meant by intention to treat analysis? survey of published randomised controlled trials. BMJ. 1999;319: 670-674.

10. Bemben DA, Fetters NL, Bemben MG, Nabavi N, Koh ET. Musculoskeletal responses to high- and low-intensity resistance training in early postmenopausal women. Med Sci Sports Exerc. 2000;32:1949-1957.

11. Campos GE, Luecke TJ, Wendeln HK, et al. Muscular adaptations in response to three different resistance-training regimens: specificity of repetition maximum training zones. Eur J Appl Physiol. 2002 Nov;88:50-60. Epub 2002 Aug 15.

12. Folland JP, Irish CS, Roberts JC, Tarr JE, Jones DA. Fatigue is not a necessary stimulus for strength gains during resistance training. Br J Sports Med. 2002;36:370-373.

13. Fleg JL, Lakatta EG. Role of muscle loss in the age-associated reduction in $\mathrm{Vo}_{2 \max } . J$ Appl Physiol. 1988;65:1147-1151.

14. Proctor DN, Joyner MJ. Skeletal muscle mass and the reduction of $\dot{V}_{\mathrm{O}_{\max }}$ in trained older subjects. J Appl Physiol. 1997;82:1411-1415.

15. Frontera WR, Meredith CN, O'Reilly KP, Evans WJ. Strength training and determinants of $\dot{\mathrm{V}}_{2 \max }$ in older men. J Appl Physiol. 1990;68:329333 .

16. Jubrias SA, Esselman PC, Price LB, Cress ME, Conley KE. Large energetic adaptations of elderly muscle to resistance and endurance training. J Appl Physiol. 2001;90:1663-1670.

17. Okazaki K, Ichinose T, Mitono H, et al. Protein and CHO supplementation during aerobic training increased plasma volume and thermoregulatory capacity in older men [abstract]. FASEB J. 2004;18:A1099. Abstract 704.7.

18. Blair SN, Goodyear NN, Gibbons LW, Cooper KH. Physical fitness and incidence of hypertension in healthy normotensive men and women. JAMA. 1984;252:487-490.

19. Sawada S, Tanaka H, Funakoshi M, Shindo M, Kono S, Ishiko T. Five year prospective study on blood pressure and maximal oxygen uptake. Clin Exp Pharmacol Physiol. 1993;20:483-487. 